\title{
Physiological and Histopathological Investigations on the Effects of $\alpha$-Lipoic Acid in Rats Exposed to Malathion
}

\author{
Atef M. Al-Attar \\ Department of Biological Sciences, Faculty of Sciences, King Abdul Aziz University, P.O. Box 139109, Jeddah 21323, Saudi Arabia \\ Correspondence should be addressed to Atef M. Al-Attar, atef_a_2000@yahoo.com
}

Received 16 January 2010; Accepted 7 March 2010

Academic Editor: Wen-Quan Zou

Copyright () 2010 Atef M. Al-Attar. This is an open access article distributed under the Creative Commons Attribution License, which permits unrestricted use, distribution, and reproduction in any medium, provided the original work is properly cited.

The present study was designed to evaluate the influence of $\alpha$-lipoic acid treatment in rats exposed to malathion. Forty adult male rats were used in this study and distributed into four groups. Animals of group 1 were untreated and served as control. Rats of group 2 were orally given malathion at a dose level of $100 \mathrm{mg} / \mathrm{kg}$ body weight (BW) for a period of one month. Experimental animals of group 3 were orally given $\alpha$-lipoic acid at a dose level of $20 \mathrm{mg} / \mathrm{kg}$ BW and after 3 hours exposed to malathion at the same dose given to group 2. Rats of group 4 were supplemented with $\alpha$-lipoic acid at the same dose given to group 3 . The activities of serum glutamic oxaloacetic acid transaminase (GOT), glutamic pyruvic acid transaminase (GPT), alkaline phosphatase (ALP), and acid phosphatase (ACP), and the values of creatinine, urea, and uric acid were statistically increased, while the values of total protein and total albumin were significantly decreased in rats exposed to malathion. Moreover, administration of malathion for one month resulted in damage of liver and kidney structures. Administration of $\alpha$-lipoic acid before malathion exposure to rat can prevent severe alterations of hematobiochemical parameters and disruptions of liver and kidney structures. In conclusion, this study obviously demonstrated that pretreatment with $\alpha$-lipoic acid significantly attenuated the physiological and histopathological alterations induced by malathion. Also, the present study identifies new areas of research for development of better therapeutic agents for liver, kidney, and other organs' dysfunctions and diseases.

\section{Introduction}

Organophosphorus compounds are widely used in agriculture, medicine, and industry. Organophosphorus pesticides, in addition to their intended effects like the control of insects or other pests, are sometimes found to affect nontarget organisms including humans $[1,2]$. Exposure to organophosphorus pesticides is also a potential cause of longer-term damage to the nervous system, with reports of poor mental health and deficits in memory and concentration [3-5]. Because of the serious environmental problems resulting from the use of pesticides in the agricultural sector, several governments are seeking to employ biological and other nonpolluting methods for combating pests. Several biocides and/or their metabolites are suggested to be prior mutagenic and/or teratogenic compounds [6-8].

Malathion (O,O-dimethyl-S-1,2-bis ethoxy carbonyl ethyl phosphorodithionate), a pesticide in the organophosphate chemical family, is the most widely used throughout the world. It is used to control the pests of agriculture crops, ornamentals, green houses, live stocks, stored grains, forests, buildings, and gardens. Contributing to its popularity is malathion's low acute mammalian toxicity. But like DDT and other pesticides that have been found to cause irreparable damage to human and environmental health, malathion may pose a greater risk than the product label would lead one to believe. Shown to be mutagenic, a possible carcinogen, implicated in vision loss, causing myriad negative health effects in human and animal studies, damaging nontarget organisms, and containing highly toxic impurities, malathion has a legacy of serious problems [9]. The toxicity of malathion is compounded by its metabolites and contaminants. Malaoxon, the metabolites produced by the oxidation of malathion in mammals, insects, and plants, is the primary source of malathion's toxicity and it is 40 times more acutely toxic than malathion $[10,11]$. Malathion is organophosphorus pesticide extensively used to control a wide range of sucking and chewing pests of field crops, 


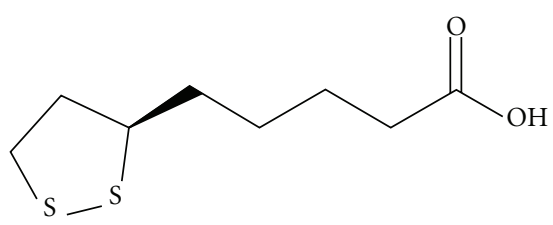

Figure 1: The chemical structure of $\alpha$-lipoic acid.

fruits and vegetables. It has many structural similarities with naturally occurring compounds, and their primary target of action in insects is the nervous system; it also inhibit the release of the acetylcholinesterase at the synaptic junction [12]. Acetylcholinesterase plays a key role in the control of nerve excitability at post synaptic sites. Malathion is found to inhibit the acetylcholinesterase. Inhibition of liver acetylcholinesterase (AChE) activity is generally regarded as a useful indicator of poisoning by organophophorous pesticides. Additionally, several studies showed that malathioninduced various physiological, biochemical, immunological, and histological changes in experimental animals [13-16].

$\operatorname{Alpha}(\alpha)$-lipoic acid (also known as thioctic acid) was discovered in 1951 as a molecule that assists in acyl-group transfer and as a coenzyme in the Krebs cycle. $\alpha$-Lipoic acid is a natural molecule consisting of a five-membered cyclic disulphide and hydrocarbon tail ending with a carboxylic acid group (Figure 1). Hence, lipoic acid is a predominantly lipophilic molecule having an amphipathic character due to its carboxylic acid group attached to the ring structure. Lipoic acid is present in our diet mainly in animal foods such as meat and liver and at low or undetectable levels in plant foods such as potato $[17,18]$. However, lipoic acid is also considered beneficial when mused as a food supplement as its antioxidant function has been previously reported and several studies have revealed its protective effects in cases such as aging, diabetes mellitus, and vascular and neurodegenerative diseases all in which free radicals are involved [19-23]. Studies are generally dealing with the biological consequences of lipoic acid administration in cases associated with oxidative stress or the differences between the antioxidant activities of lipoic acid and its derivatives [19, $22,24,25]$. Data on the efficacy and biological activity of $\alpha$ lipoic acid on malathion intoxication are not available. In the present study, an attempt was made to elucidate the possible protective effect of $\alpha$-lipoic acid treatment on malathioninduced physiological and histopathological alterations in rats. Rats have been selected for present study as they have physiological systems and responses similar to those of man. They have also remarkable genetic similarities to human.

\section{Materials and Methods}

2.1. Animals. Forty Wistar male rats weighing $200-220 \mathrm{~g}$ were obtained from the Experimental Animal Unit of King Fahd Medical Research Center, King Abdul Aziz University, Jeddah, Saudi Arabia. Rats were acclimatized to the experimental room having temperature $19 \pm 1^{\circ} \mathrm{C}$, controlled humidity conditions (65\%), and 12:12 hour light: dark cycle. The experimental animals were housed in standard plastic cages, fed with standard diet, and water ad libitum. All experimental procedures were approved by the Animal Care and Use Committee of King Abdul Aziz University.

2.2. Experimental Design. After acclimatization period, rats were divided into four groups comprising ten animals in each group as follows.

- Group 1. Rats were untreated and served as control.

- Group 2. Experimental animals were orally given malathion at a dose level of $100 \mathrm{mg} / \mathrm{kg}$ body weight (BW), for a period of one month.

- Group 3. The animals were orally given $\alpha$-lipoic acid (Sigma Chemical Company, St. Louis, Mo, USA) solution at a dose level of $20 \mathrm{mg} / \mathrm{kg}$ BW and after 3 hours treated with malathion at the same dose given to group 2.

- Group 4. Animals were treated with $\alpha$-lipoic acid at the same dose given to group 3 .

2.3. Hematobiochemical Analysis. At the end of experimental period, rats were anaesthetized with ether. Blood samples were collected from orbital venous plexus in nonheparinized tubes, centrifuged at $2000 \mathrm{rpm}$ for 20 minutes, and blood sera were then collected and stored at $4{ }^{\circ} \mathrm{C}$ prior immediate determination of glutamic oxaloacetic acid transaminase (GOT), glutamic pyruvic acid transaminase (GPT), alkaline phosphatase (ALP), acid phosphatase (ACP), total protein, total albumin, creatinine, urea, and uric acid. All of these parameters were measured using Automated Clinical Chemistry Analysis System, Dimension type RXL Max (Dade Behring Delaware, DE 19714, U.S.A.).

2.4. Histopathological Examination. For light microscopic examination, liver and kidney tissues from each groups were fixed with $10 \%$ buffered formalin, embedded with paraffin. After routine processing, paraffin sections of each tissue were cut into $4 \mu \mathrm{m}$ thickness and stained with haematoxylin and eosin.

2.5. Statistical Analysis. The results of hematobiochemical analysis were analyzed using the Statistical Package for Social Sciences (SPSS for windows, version 12.0). Comparisons were made between experimental groups using one-way analysis of variance (ANOVA) followed by Dunnett's test. Values of less than 0.05 were regarded as statistically significant.

\section{Results}

Table 1 shows the values of serum GOT, GPT, ALP, ACP, total protein, total albumin, creatinine, urea and uric acid in all experimental groups. In comparison with control values, the levels of GOT (206.5\%), GPT (185.3\%), ALP (95.0\%), ACP $(51.6 \%)$, creatinine $(73.1 \%)$, urea $(27.8 \%)$, and uric acid $(32.1 \%)$ were statistically increased, while the levels of total 
TABLE 1: Changes in values of serum GOT, GPT, ALP, ACP, total protein, total albumin, creatinine, urea, and uric acid in rats treated with malathion, malathion plus $\alpha$-lipoic acid, and $\alpha$-lipoic acid. Tabulated values are means of ten determinations \pm standard deviation (SD).

\begin{tabular}{|c|c|c|c|c|}
\hline \multirow{2}{*}{ Parameters } & \multicolumn{4}{|c|}{ Treatment } \\
\hline & Control & Malathion & Malathion $+\alpha$-Lipoic acid & $\alpha$-lipoic acid \\
\hline GOT $\left(\mathrm{UL}^{-1}\right)$ & $61.80 \pm 3.29$ & $189.40 \pm 13.62^{\mathrm{a}, \mathrm{b}}$ & $115.30 \pm 5.8^{\mathrm{a}}$ & $56.70 \pm 6.52$ \\
\hline $\mathrm{GPT}\left(\mathrm{UL}^{-1}\right)$ & $39.50 \pm 3.17$ & $112.70 \pm 9.99^{\mathrm{a}, \mathrm{b}}$ & $64.30 \pm 7.84^{\mathrm{a}}$ & $38.20 \pm 2.52$ \\
\hline $\operatorname{ALP}\left(\mathrm{UL}^{-1}\right)$ & $324.40 \pm 10.86$ & $632.70 \pm 29.89^{\mathrm{a}, \mathrm{b}}$ & $395.30 \pm 37.05^{\mathrm{a}}$ & $339.20 \pm 20.61$ \\
\hline $\operatorname{ACP}\left(\mathrm{UL}^{-1}\right)$ & $109.80 \pm 9.25$ & $166.40 \pm 27.69^{\mathrm{a}, \mathrm{b}}$ & $139.30 \pm 17.17^{\mathrm{a}}$ & $114.20 \pm 13.58$ \\
\hline Total protein $\left({\left.\mathrm{g} 100 \mathrm{~mL}^{-1}\right)}^{-1}\right.$ & $6.75 \pm 0.28$ & $5.51 \pm 0.30^{\mathrm{a}, \mathrm{b}}$ & $6.64 \pm 0.38$ & $6.73 \pm 0.28$ \\
\hline Total albumin $\left(\mathrm{g} 100 \mathrm{~mL}^{-1}\right)$ & $3.18 \pm 0.19$ & $2.86 \pm 0.20^{\mathrm{a}, \mathrm{b}}$ & $3.13 \pm 0.23$ & $3.24 \pm 0.25$ \\
\hline Creatinine $\left(\mathrm{mg} 100 \mathrm{~mL}^{-1}\right)$ & $0.67 \pm 0.05$ & $1.16 \pm 0.24^{\mathrm{a}, \mathrm{b}}$ & $0.82 \pm 0.11^{\mathrm{a}}$ & $0.70 \pm 0.08$ \\
\hline Urea $\left(\mathrm{mg} 100 \mathrm{~mL}^{-1}\right)$ & $23.56 \pm 1.77$ & $30.12 \pm 2.45^{\mathrm{a}, \mathrm{b}}$ & $25.28 \pm 1.92$ & $22.74 \pm 2.04$ \\
\hline Uric acid $\left(\mathrm{mg} 100 \mathrm{~mL}^{-1}\right)$ & $3.71 \pm 0.27$ & $4.90 \pm 0.47^{\mathrm{a}, \mathrm{b}}$ & $4.01 \pm 0.36$ & $3.86 \pm 0.26$ \\
\hline
\end{tabular}

a: Indicates a significant difference between control and treated groups.

b: Indicates a significant difference between the group treated with malathion and groups treated with malathion plus $\alpha$-lipoic acid and $\alpha$-lipoic acid.

protein (18.4\%) and total albumin (10.6\%) were significantly decreased in rats exposed to malathion, group 2. Significant elevations in the levels of serum GOT (86.8\%), GPT (62.8\%), ALP (21.9\%), ACP (26.9\%), and creatinine (22.4\%) were observed in rats exposed to malathion plus $\alpha$-lipoic acid (group 3), while the levels of total protein, total albumin, urea, and uric acid were statistically unchanged compared with control values. From Table 1, it's obviously that $\alpha$ lipoic acid notably lowered the percentage elevations of these parameters in malathion treated rats. Moreover, insignificant changes in the levels of serum hematobiochemical parameters were noted in rats treated with only $\alpha$-lipoic acid, group 4.

Light microscopic examination of the liver of control rats showed the normal structure in Figure 2(a). Histopathological effects of malathion on liver of treated rats are presented in Figures 2(b) and 2(c). Rats treated with malathion showed many severe histopathological alterations. Administration of malathion for one month resulted in the damage of liver structure along with disarrangement of hepatic strands. Several cells also show histological features of necrosis. Moreover, an enlargement of the sinusoids and vacuole formations in hepatocytes, leucocytic infiltrations, dilation, and congestion of blood vessels with hemorrhage were noted in liver of rats exposed to malathion (group 2). $\alpha$-Lipoic acid treatment brought back the cellular arrangement around the central vein and reduced necrosis (Figure 2(d)). Also, it helped to bring the blood vessels to normal condition. Mild to moderate enlargement in the sinusoids, vacuole formations in hepatocytes, leucocytic infiltrations, dilation and congestion of blood vessels with hemorrhage were observed in rats treated with malathion plus $\alpha$-lipoic acid compared with malathion treated rats and control rats. Figure 3 shows the histology structures of the kidney in control group (Figure 3(a)), malathion treated rats (Figures 3(b) and 3(c)), and malathion plus $\alpha$-lipoic acid treated rats (Figure $3(\mathrm{~d})$ ). Areas of renal cortex containing renal corpuscles and associated tubules showed more pronounced changes in treated animals compared with control. Therefore, these areas were selected for histological examination with the light microscope. The normal renal corpuscle consists of a tuft of capillaries, the glomerulus, surrounded by a double-walled epithelial capsule called Bowman's capsule. Between the two layers of the capsule is the urinary or Bowman's space (Figure 3(a)). In one-month malathion-dosed rats, there were pronounced changes in the structure of renal corpuscle including swelling appearances, increasing of urinary spaces, highly degeneration of glomeruli, Bowman's capsules and associated tubules structure (Figures 3(b) and 3(c)). $\alpha$-Lipoic acid treatment reversed abnormal histology of renal cortex areas induced by malathion intoxication (Figure 3(d)). Renal corpuscles in this group were appeared more as normal as shown in Figure 3(a) and the most changes were noted in the structure of some glomeruli. Additionally, no detectable histological differences are observed by the light microscope between control rats and rats supplemented with only $\alpha$ lipoic acid, group 4.

\section{Discussion}

The present investigation indicates that oral administration of malathion to rats caused significant alterations in hematobiochemical parameters. The activities of serum GOT, GPT, ALP, ACP, and the levels of creatinine, urea, and uric acid were significantly increased, while the values of total protein and total albumin were statistically decreased. These results are in agreement with different previous researches which indicated that the exposure to malathion and other pesticides led to induce severe physiological and biochemical disturbances in experimental animals, buffalo calves [26], goats [27], mice [28], cockerels [29], poultry [30], rabbits [31], and rats [32-39]. In addition, malathion induced severe hepatic and renal damages as shown in histopathological examination which coupled with markedly elevated levels of liver hemato-biochemical markers (GOT, GPT, ALP, and $\mathrm{ACP}$ ) and significant changes of kidney hemato-biochemical indices including statistically increased levels of creatinine, urea and uric acid, and decreased levels of total protein and albumin concentrations. Tos-Luty et al. [40] showed that 


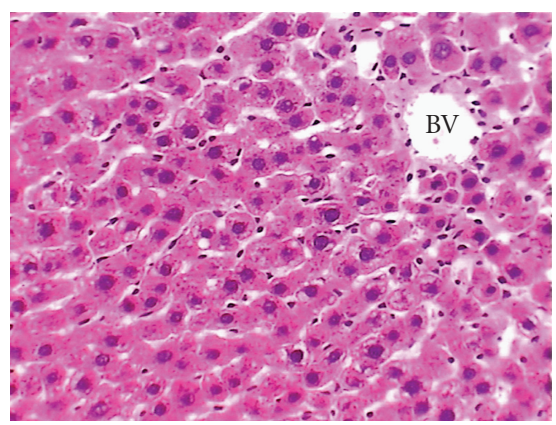

(a)

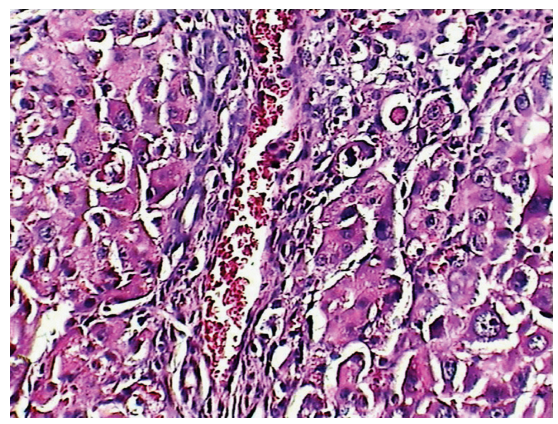

(c)

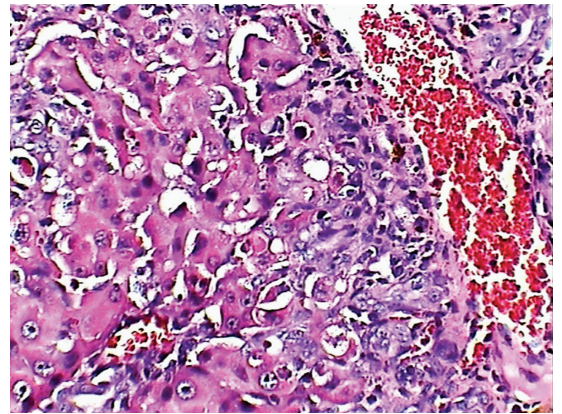

(b)

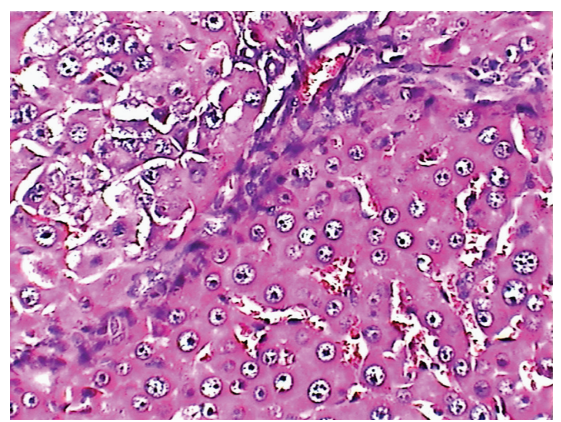

(d)

FIgURE 2: Liver micrographs of control (a), malathion ((b) and (c)), and malathion plus $\alpha$-lipoic acid (d) treated rats. Original magnification X400.

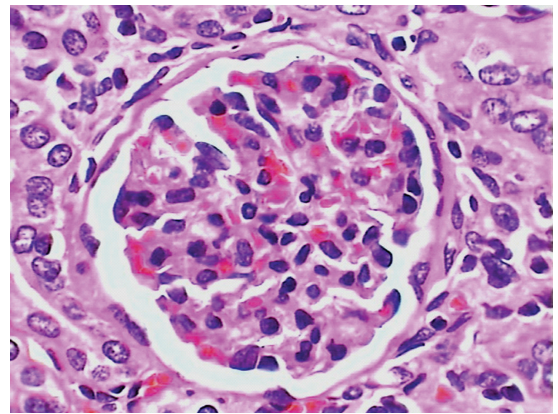

(a)

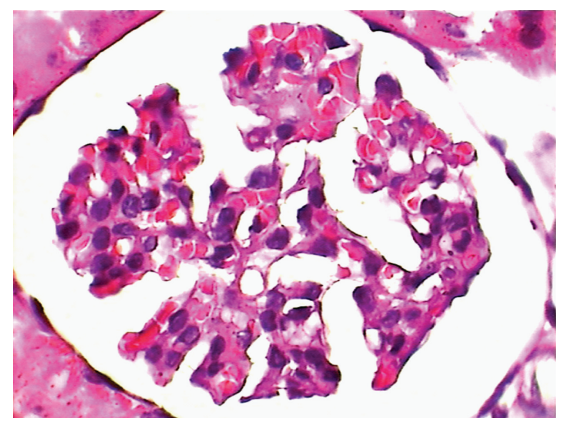

(c)

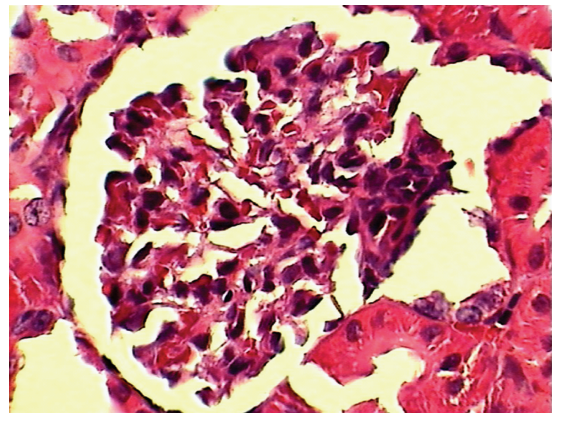

(b)

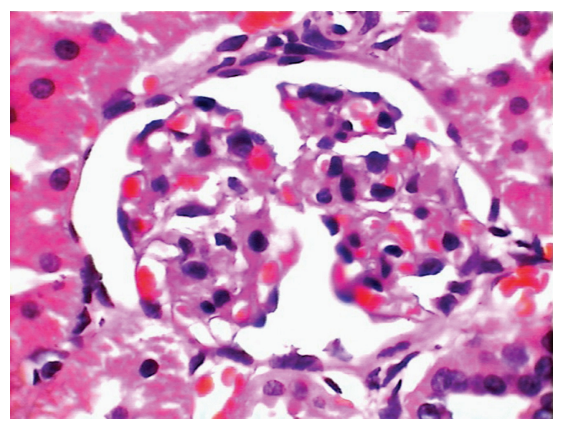

(d)

FIgURE 3: Renal corpuscle micrographs of control (a), malathion ((b) and (c)), and malathion plus $\alpha$-lipoic acid (d) treated rats. Original magnification X400. 
malathion intoxication led to severe effects on the structures of the liver and kidney including the presence of fine subcapsular infiltrations, diffused parenchymatous degeneration of single hepatocytes, and the presence of fine foci constructed of plasmatic cells, and histiocytes located between hepatic plates. In the submicroscopic structure of hepatocytes, there occurred lucent areas of cytoplasm containing the residues of cell organelle and lipid vacuoles. Mitochondria were usually swollen, showing a clearance of the matrix and destruction of crists. Additionally, they showed that the histopathological changes in the kidneys occurred in all animals. These changes covered parenchymatous degeneration of the cells of renal tubules and hyperemia of the cortical part of the kidney, especially of renal glomeruli, as well as infiltrations were noted. In the ultrastructure of the cells of renal proximal tubules, vacuoles with damaged external membrane were observed, as well as swollen and pleomorphic mitochondria. However, different studies showed that malathion and other pesticides induced liver and kidney histopathological alterations in experimental animals $[16,38,41-43]$.

The present study showed that the administration of $\alpha$-lipoic acid before malathion exposure to rat can prevent severe changes of hematobiochemical parameters and disruptions of liver and kidney structures. Sandhya and Varalakshmi [44] and Malarkodi et al., [45] showed that the pretreatment of rats with $\alpha$-lipoic acid protected against nephrotoxicity induced by gentamicin and adriamycin. Suntres [46] stated that the administration of lipoic acid prior to lipopolysaccharide challenge resulted in a significant alleviation of liver injuries, evidenced by a general reversal of the altered biochemical indices toward normal among treated animals. Pari and Murugavel [47] reported that the increased level of serum enzymes (GPT, GOT, and ALP), bilirubin, lipids and plasma thiobarbituric acid-reactive substances (TBARS), and hydroperoxides observed in rats treated with chloroquine were very much reduced in rats treated with $\alpha$ lipoic acid plus chloroquine. A significant decrease in plasma antioxidants such as reduced glutathione (GSH), vitamin $\mathrm{C}$, and vitamin $\mathrm{E}$ were observed in chloroquine-treated rats when compared with control rats. Administration of $\alpha$-lipoic acid significantly improved the levels of plasma antioxidants $\mathrm{GSH}$, vitamin $\mathrm{C}$, and vitamin $\mathrm{E}$ in chloroquine-treated rats. Moreover, they stated that the results revealed that $\alpha$-lipoic acid could offer protection against chloroquine-induced hepatotoxicity. Dulundu et al. [48] demonstrated that serum GPT, GOT, and lactate dehydrogenase (LDH) activities and cytokine, TNF-alpha and IL-1beta levels were elevated in the ischemia/reperfusion rats group, while this increase was significantly lower in the group of animals treated concomitantly with lipoic acid. Hepatic glutathione (GSH) levels, significantly depressed by ischemia/reperfusion, were elevated back to control levels in lipoic acid-treated ischemia/reperfusion group. Furthermore, increases in tissue luminol and lucigenin chemiluminescence (CL), malondialdehyde (MDA) levels, and myeloperoxidase (MPO) activity due to ischemia/reperfusion injury were reduced back to control levels with lipoic acid treatment. Since lipoic acid administration alleviated the ischemia/reperfusion-induced liver injury and improved the hepatic structure and function, it seems likely that lipoic acid with its antioxidant and oxidant-scavenging properties may be of potential therapeutic value in protecting the liver against oxidative injury due to ischemia/reperfusion. Also, Abdel-Zaher et al. [49] reported that the pretreatment of rats with $\alpha$-lipoic acid orally protected markedly against hepatotoxicity and nephrotoxicity induced by an acute oral toxic dose of acetaminophen as assessed by biochemical measurements and by histopathological examinations. Sehirli et al. [50] showed that $\alpha$-lipoic acid treatment reversed all of examined renal biochemical indices, as well as histopathological alterations induced by ischaemia-reperfusion in rats. They suggested that $\alpha$ lipoic acid protects kidney tissues by inhibiting neutrophil infiltration, balancing the oxidant-anti-oxidant status, and regulating the generation of inflammatory mediators. Shanmugarajan et al. [51] evaluated the effect of $\alpha$-lipoic acid supplementation on acute D-galactosamine-induced oxidative liver injury. Hepatotoxicity induced by D-galactosamine was evident from increase in lipid peroxidation and serum marker enzymes (GOT, GPT, ALP, and LDH). The decreased activities of enzymic antioxidants (superoxide dismutase, catalase, glutathione peroxidase, and glutathione reductase) as well as glutathione levels were the salient features observed in D-galactosamine-induced hepatotoxicity. Pretreatment with $\alpha$-lipoic acid significantly precluded these changes and prevents the hepatic injury induced by $\mathrm{D}$-galactosamine. In the study of Kang et al. [52], they showed that cisplatininduced decreases in renal function, measured by blood urea nitrogen, serum creatinine level, and renal tubular injury scores, were attenuated by $\alpha$-Lipoic acid treatment. Additionally, $\alpha$-lipoic acid decreased the tissue levels of tumour necrosis factor- $\alpha$, the expression of intercellular adhesion molecule-1 (ICAM-1), and monocyte chemoattractant protein-1 (MCP-1), and suppressed the infiltration of CD11b-positive macrophages. $\alpha$-Lipoic acid also attenuated the cisplatin-induced increases in the phosphorylation and nuclear translocation of NF-B p65 subunits in kidney tissue.

Organophosphorus compounds may induce oxidative stress leading to the generation of free radicals and alterations in antioxidant and scavengers of oxygen-free radicals. However, several studies showed that malathion induced lipid peroxidation and oxidative stress in experimental animals [53-57]. $\alpha$-Lipoic acid taken up by the cells where it is converted to dihydrolipoic acid (DHLA) by glutathione reductase, thioredoxin reductase (TrxR), and LDH and extensively metabolized by $\beta$-oxidation, in tissue. The metabolites of $\alpha$-lipoic acid and DHLA also suggested to play a significant role in the treatment of various pathological conditions [58]. Reactive oxygen species (ROS) and reactive nitrogen species (RNS) are produced as byproducts of oxidative metabolism. However, high levels of ROS and RNS have been considered to potentially damage cellular macromolecules and have been implicated in the pathogenesis and progression of various chronic diseases. Several lines of evidence indicate that $\alpha$-lipoic acid exerts potent antioxidant activity in vitro and in vivo [59]. $\alpha$-Lipoic acid acts by multiple mechanisms both physiologically and pharmacologically. Pharmacologically, it improves glycemic 
control, polyneuropathy. Physiologically as an antioxidant, $\alpha$-lipoic acid directly terminates free radicals, chelates metal ions, and increases cytosolic glutathione and vitamin $\mathrm{C}$ [60]. However, the exact mechanism action by which $\alpha$ lipoic acid attenuates the severe influences of malathion exposure to rats is unknown. Although the data obtained in the present study do not allow any definite conclusions to be drawn on the mechanism action of $\alpha$-lipoic acid in malathion-treated experimental animals, it is possible that inhibition of malathion-induced severe physiological and histopathological alterations in rats by $\alpha$-lipoic acid supplementation may be mediated through the modulation of malathion metabolism. Also, it cannot be excluded that the possibility that $\alpha$-lipoic acid offers protection against reactive oxygen species-mediated damage by enhancing cellular antioxidant defense and reducing severe physiological and histopathological alterations in rats exposed to malathion. In conclusion, the present findings show that oral administration of $\alpha$-lipoic acid produces significant antihepatotoxicity and nephrotoxicity effects in malathion treated rats. Further investigations are required to explore exactly the mechanism action of $\alpha$-lipoic acid against malathioninduced physiological disturbances and histopathological changes. Finally, the present study identifies new areas of research for development of better therapeutic agents for liver, kidney, and other organs' dysfunctions and diseases.

\section{References}

[1] G. Cantelli-Forti, M. Paolini, and P. Hrelia, "Multiple end point procedure to evaluate risk from pesticides," Environmental Health Perspectives, vol. 101, supplement 3, pp. 15-20, 1993.

[2] K. Chaudhuri, S. Selvaraj, and A. K. Pal, "Studies on the genotoxicity of endosulfan in bacterial systems," Mutation Research, vol. 439, no. 1, pp. 63-67, 1999.

[3] J. E. Davis, "Neurotoxic concerns of human pesticide exposures," American Journal of Industrial Medicine, vol. 18, no. 3, pp. 327-331, 1991.

[4] H. J. Mason, "The recovery of plasma cholinesterase and erythrocyte acetylcholinesterase activity in workers after overexposure to dichlorvos," Occupational Medicine, vol. 50, no. 5, pp. 343-347, 2000.

[5] H. N. Nigg and J. B. Knaak, "Blood cholinesterases as human biomarkers of organophosphorus pesticide exposure," Reviews of Environmental Contamination \& Toxicology, vol. 163, pp. 29-111, 2000.

[6] R. L. Ridgway, J. C. Tinney, J. T. MacGregor, and N. J. Starler, "Pesticide use in agriculture," Environmental Health Perspectives, vol. 27, pp. 103-112, 1978.

[7] L. Fishbein, "An overview of structural features of some mutagenic and teratogenic pesticides," in Effect of Chronic Exposure to Pesticides on Animal Systems, J. E. Chembers and J. D. Yarbrough, Eds., pp. 177-209, Raven Press, New York, NY, USA, 1982.

[8] A. M. El-Sharkawy, S. Z. Abdel-Rahman, A. A. Hassan, M. H. Gabr, S. M. El-Zoghby, and S. M. El-Sewedy, "Biochemical effects of some insecticides on the metabolic enzymes regulating glutathione metabolism," Bulletin of Environmental Contamination and Toxicology, vol. 52, no. 4, pp. 505-510, 1994.
[9] L. Brenner, "Malathion fact sheet," Journal of Pesticide Reform, vol. 12, pp. 1-17, 1992.

[10] J. Brodeur and K. P. DuBois, "Studies on factors influencing the acute toxicity of malathion and malaoxon in rats," Canadian Journal of Physiology and Pharmacology, vol. 45, no. 4, pp. 621-631, 1967.

[11] W. N. Aldridge, J. W. Miles, D. L. Mount, and R. D. Verschoyle, "The toxicological properties of impurities in malathion," Archives of Toxicology, vol. 42, no. 2, pp. 95-106, 1979.

[12] G. Cabello, M. Valenzuela, A. Vilaxa, et al., "A rat mammary tumor model induced by the organophosphorous pesticides parathion and malathion, possibly through acetylcholinesterase inhibition," Environmental Health Perspectives, vol. 109, no. 5, pp. 471-479, 2001.

[13] A. Bhatia, M. Makkar, and N. Sohal, "Effect of subchronic and sublethal doses of malathion on some haematological and immunological parameters," International Journal of Environmental Studies, vol. 51, no. 1, pp. 59-66, 1996.

[14] R. Rezg, B. Mornagui, M. El-Arbi, A. Kamoun, S. El-Fazaa, and N. Gharbi, "Effect of subchronic exposure to malathion on glycogen phosphorylase and hexokinase activities in rat liver using native PAGE," Toxicology, vol. 223, no. 1-2, pp. 9-14, 2006.

[15] R. Rezg, B. Mornagui, A. Kamoun, S. El-Fazaa, and N. Gharbi, "Effect of subchronic exposure to malathion on metabolic parameters in the rat," Comptes Rendus Biologies, vol. 330, no. 2, pp. 143-147, 2007.

[16] L. Saadi, N. Lebaili, and M. Benyoussi, "Exploration of cytotoxic effect of malathion on some rat organs structure," Communications in Agricultural and Applied Biological Sciences, vol. 73, no. 4, pp. 875-881, 2008.

[17] H. Kataoka, "Chromatographic analysis of lipoic acid and related compounds," Journal of Chromatography B, vol. 717, no. 1-2, pp. 247-262, 1998.

[18] J. Lachman, K. Hamouz, M. Orsak, and V. Pivec, "Potato tubers as a significant source of antioxidants in human nutrition,” Rostlinna Vyroba, vol. 46, no. 5, pp. 231-236, 2000.

[19] L. Packer, H. J. Tritschler, and K. Wessel, "Neuroprotection by the metabolic antioxidant $\alpha$-lipoic acid," Free Radical Biology and Medicine, vol. 22, no. 1-2, pp. 359-378, 1996.

[20] T. M. Hagen, R. T. Ingersoll, J. Lykkesfeldt, et al., “(R)- $\alpha$ lipoic acid-supplemented old rats have improved mitochondrial function, decreased oxidative damage, and increased metabolic rate," FASEB Journal, vol. 13, no. 2, pp. 411-418, 1999.

[21] L. Packer, K. Kraemer, and G. Rimbach, "Molecular aspects of lipoic acid in the prevention of diabetes complications," Nutrition, vol. 17, no. 10, pp. 888-895, 2001.

[22] O. Yilmaz, Y. Ozkan, M. Yildirim, A. I. Ozturk, and Y. Ersan, "Effects of alpha lipoic acid, ascorbic acid-6-palmitate, and fish oil on the glutathione, malonaldehyde, and fatty acids levels in erythrocytes of streptozotocin induced diabetic male rats," Journal of Cellular Biochemistry, vol. 86, no. 3, pp. 530539, 2002.

[23] S. D. Wollin and P. J. H. Jones, " $\alpha$-lipoic acid and cardiovascular disease," Journal of Nutrition, vol. 133, no. 11, pp. 33273330, 2003.

[24] S. Matsugo, L.-J. Yan, T. Konishi, et al., "The lipoic acid analogue 1,2-diselenolane-3-pentanoic acid protects human low density lipoprotein against oxidative modification mediated by copper ion," Biochemical and Biophysical Research Communications, vol. 240, no. 3, pp. 819-824, 1997.

[25] P. Arivazhagan, T. Thilakavathy, K. Ramanathan, S. Kumaran, and C. Panneerselvam, "Effect of DL- $\alpha$-lipoic acid on the 
status of lipid peroxidation and protein oxidation in various brain regions of aged rats," The Journal of Nutritional Biochemistry, vol. 13, no. 10, pp. 619-624, 2002.

[26] G. Singh, L. D. Sharma, A. H. Ahmad, and S. P. Singh, "Fenvalerate induced dermal toxicity in buffalo calves," Journal of Applied Animal Research, vol. 16, no. 2, pp. 205-210, 1999.

[27] H. Kaur, A. K. Srivastava, S. K. Garg, and D. Prakash, "Subacute oral toxicity of chlorpyriphos in goats with particular reference to blood biochemical and pathomorpholigical alteration," Indian Journal of Toxicology, vol. 7, no. 2, pp. 8390, 2000.

[28] M. Mohssen, "Biochemical and histopathological changes in serum creatinine and kidney induced by inhalation of Thimet (phorate) in male Swiss albino mouse, Mus musculus," Environmental Research, vol. 87, no. 1, pp. 31-36, 2001.

[29] S. P. Singh, L. D. Sharma, S. P. Singh, and A. H. Ahmad, "Haematobiochemical profiles in cockerels following prolong feeding of fenvalerate," Indian Journal of Agronomy, vol. 8, no. 2, pp. 141-145, 2003.

[30] U. Jayasree, A. Gopala Reddy, K. S. Reddy, and B. Kalakumar, "Study on the mechanism of toxicity of deltamethrin in poultry," Indian Journal of Toxicology, vol. 10, no. 2, pp. 111$114,2003$.

[31] M. I. Yousef, F. M. El-Demerdash, K. I. Kamel, and K. S. Al-Salhen, "Changes in some hematological and biochemical indices of rabbits induced by isoflavones and cypermethrin," Toxicology, vol. 189, no. 3, pp. 223-234, 2003.

[32] A. Jabbar, S. A. Khawaja, A. Iqbal, and S. A. Malik, "Effect of malathion and methyl-parathion on rat liver enzymes," Journal of the Pakistan Medical Association, vol. 40, no. 11, pp. 266-270, 1990.

[33] M. A. Shah and P. K. Gupta, "Subacute toxicity studies on permethrin," Indian Journal of Toxicology, vol. 8, no. 1, pp. 6167, 2001.

[34] N. Choudhary and S. C. Joshi, "Effect of short term endosulfan on haematology and serum analysis of male rat," Indian Journal of Toxicology, vol. 9, no. 2, pp. 83-87, 2002.

[35] U. K. Garg, A. K. Pal, G. J. Jha, and S. B. Jadhao, "Haematobiochemical and immuno-pathophysiological effects of chronic toxicity with synthetic pyrethroid, organophosphate and chlorinated pesticides in broiler chicks," International Immunopharmacology, vol. 4, no. 13, pp. 1709-1722, 2004.

[36] O. Y. Adeniran, M. A. Fafunso, O. Adeyemi, A. O. Lawal, A. Ologundudu, and A. A. Omonkhua, "Biochemical effects of pesticides on serum and urinological system of rats," Journal of Applied Sciences, vol. 6, no. 3, pp. 668-672, 2006.

[37] O. E. Etim, E. O. Farombi, I. F. Usoh, and E. J. Akpan, "The protective effect of aloe vera juice on lindane induced hepatotoxicity and genotoxicity," Pakistan Journal of Pharmaceutical Sciences, vol. 19, no. 4, pp. 337-340, 2006.

[38] M. Kerem, N. Bedirli, N. Gurbuz, et al., "Effects of acute fenthion toxicity on liver and kidney function and histology in rats," Turkish Journal of Medical Sciences, vol. 37, no. 5, pp. 281-288, 2007.

[39] A. A. Attia and H. M. Nasr, "Dimethoate-induced changes in biochemical parameters of experimental rat serum and its neutralization by black seed (Nigella sativa L.) oil," Slovak Journal of Animal Science, vol. 42, no. 2, pp. 87-94, 2009.

[40] S. Tos-Luty, D. Obuchowska-Przebirowska, J. Latuszynska, M. Tokarska-Rodak, and A. Haratym-Maj, "Dermal and oral toxicity of malathion in rats," Annals of Agriculture and Environmental Medicine, vol. 10, no. 1, pp. 101-106, 2003.

[41] A. Yavasoglu, F. Sayim, Y. Uyanikgil, M. Turgut, and N. U. Karabay-Yavasoglu, "The pyrethroid cypermethrin-induced biochemical and histological alterations in rat liver," Journal of Health Science, vol. 52, no. 6, pp. 774-780, 2006.

[42] H. Abdel Razik, Farrag, and S. E. M. Shalby, "Comparative histopathological and histochemical studies on IGR, lufenuron and profenofos insecticide albino rats," Journal of Applied Sciences Research, vol. 3, no. 5, pp. 377-386, 2007.

[43] S. Afshar, A. A. Farshid, R. Heidari, and M. Ilkhanipour, "Histopathological changes in the liver and kidney tissues of Wistar albino rat exposed to fenitrothion," Toxicology and Industrial Health, vol. 24, no. 9, pp. 581-586, 2008.

[44] P. Sandhya and P. Varalakshmi, "Effect of lipoic acid administration on gentamicin-induced lipid peroxidation in rats," Journal of Applied Toxicology, vol. 17, no. 6, pp. 405-408, 1997.

[45] K. P. Malarkodi, A. V. Balachandar, and P. Varalakshmi, "The influence of lipoic acid on adriamycin induced nephrotoxicity in rats," Molecular and Cellular Biochemistry, vol. 247, no. 1-2, pp. 15-22, 2003.

[46] Z. E. Suntres, "Prophylaxis against lipopolysaccharideinduced liver injuries by lipoic acid in rats," Pharmacological Research, vol. 48, no. 6, pp. 585-591, 2003.

[47] L. Pari and P. Murugavel, "Protective effect of $\alpha$-lipoic acid against chloroquine-induced hepatotoxicity in rats," Journal of Applied Toxicology, vol. 24, no. 1, pp. 21-26, 2004.

[48] E. Dulundu, Y. Ozel, U. Topaloglu, et al., "Alpha-lipoic acid protects against hepatic ischemia-reperfusion injury in rats," Pharmacology, vol. 79, no. 3, pp. 163-170, 2007.

[49] A. O. Abdel-Zaher, R. H. Abdel-Hady, M. M. Mahmoud, and M. M. Y. Farrag, "The potential protective role of alphalipoic acid against acetaminophen-induced hepatic and renal damage," Toxicology, vol. 243, no. 3, pp. 261-270, 2008.

[50] O. Sehirli, E. Sener, S. Cetinel, M. Yüksel, N. Gedik, and G. Sener, " $\alpha$-lipoic acid protects against renal ischaemiareperfusion injury in rats," Clinical and Experimental Pharmacology and Physiology, vol. 35, no. 3, pp. 249-255, 2008.

[51] T. S. Shanmugarajan, D. Sivaraman, I. Somasundaram, et al., "Influence of alpha lipoic acid on antioxidant status in D-galactosamine-induced hepatic injury," Toxicology and Industrial Health, vol. 24, no. 10, pp. 635-642, 2008.

[52] K. P. Kang, D. H. Kim, Y. J. Jung, et al., "Alpha-lipoic acid attenuates cisplatin-induced acute kidney injury in mice by suppressing renal inflammation," Nephrology Dialysis Transplantation, vol. 24, no. 10, pp. 3012-3020, 2009.

[53] R. S. Ahmed, V. Seth, S. T. Pasha, and B. D. Banerjee, "Influence of dietary ginger (Zingiber officinales Rosc) on oxidative stress induced by malathion in rats," Food and Chemical Toxicology, vol. 38, no. 5, pp. 443-450, 2000.

[54] M. Akhgari, M. Abdollahi, A. Kebryaeezadeh, R. Hosseini, and O. Sabzevari, "Biochemical evidence for free radical-induced lipid peroxidation as a mechanism for subchronic toxicity of malathion in blood and liver of rats," Human \& Experimental Toxicology, vol. 22, no. 4, pp. 205-211, 2003.

[55] J. J. Fortunato, F. R. Agostinho, G. Z. Réus, F. C. Petronilho, F. Dal-Pizzol, and J. Quevedo, "Lipid peroxidative damage on malathion exposure in rats," Neurotoxicity Research, vol. 9, no. 1, pp. 23-28, 2006.

[56] A. P. da Silva, M. Farina, J. L. Franco, A. L. Dafre, J. Kassa, and K. Kuca, "Temporal effects of newly developed oximes (K027, K048) on malathion-induced acetylcholinesterase inhibition and lipid peroxidation in mouse prefrontal cortex," NeuroToxicology, vol. 29, no. 1, pp. 184-189, 2008.

[57] J. L. Franco, T. Posser, J. J. Mattos, et al., "Zinc reverses malathion-induced impairment in antioxidant defenses," Toxicology Letters, vol. 187, no. 3, pp. 137-143, 2009. 
[58] W. Jones, X. Li, Z.-C. Qu, L. Perriott, R. R. Whitesell, and J. M. May, "Uptake, recycling, and antioxidant actions of $\alpha$-lipoic acid in endothelial cells," Free Radical Biology and Medicine, vol. 33, no. 1, pp. 83-93, 2002.

[59] T. W. Nichols Jr., " $\alpha$-lipoic acid: biological effects and clinical implications," Alternative Medicine Review, vol. 2, no. 3, pp. 177-183, 1997.

[60] M. T. Islam, "Antioxidant activities of dithiol alpha-lipoic acid," Bangladesh Journal of Medical Science, vol. 8, no. 3, pp. 46-51, 2009. 

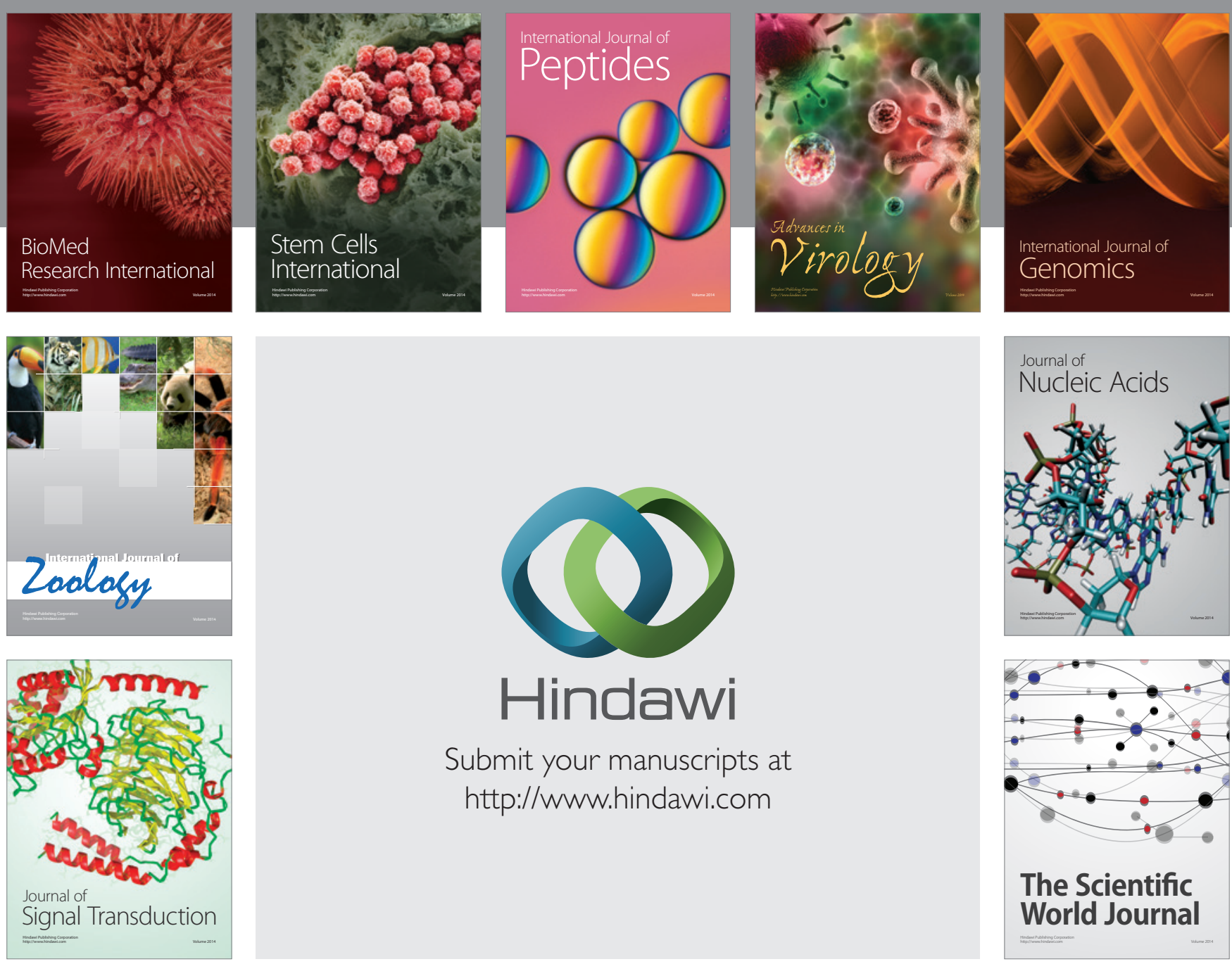

Submit your manuscripts at

http://www.hindawi.com
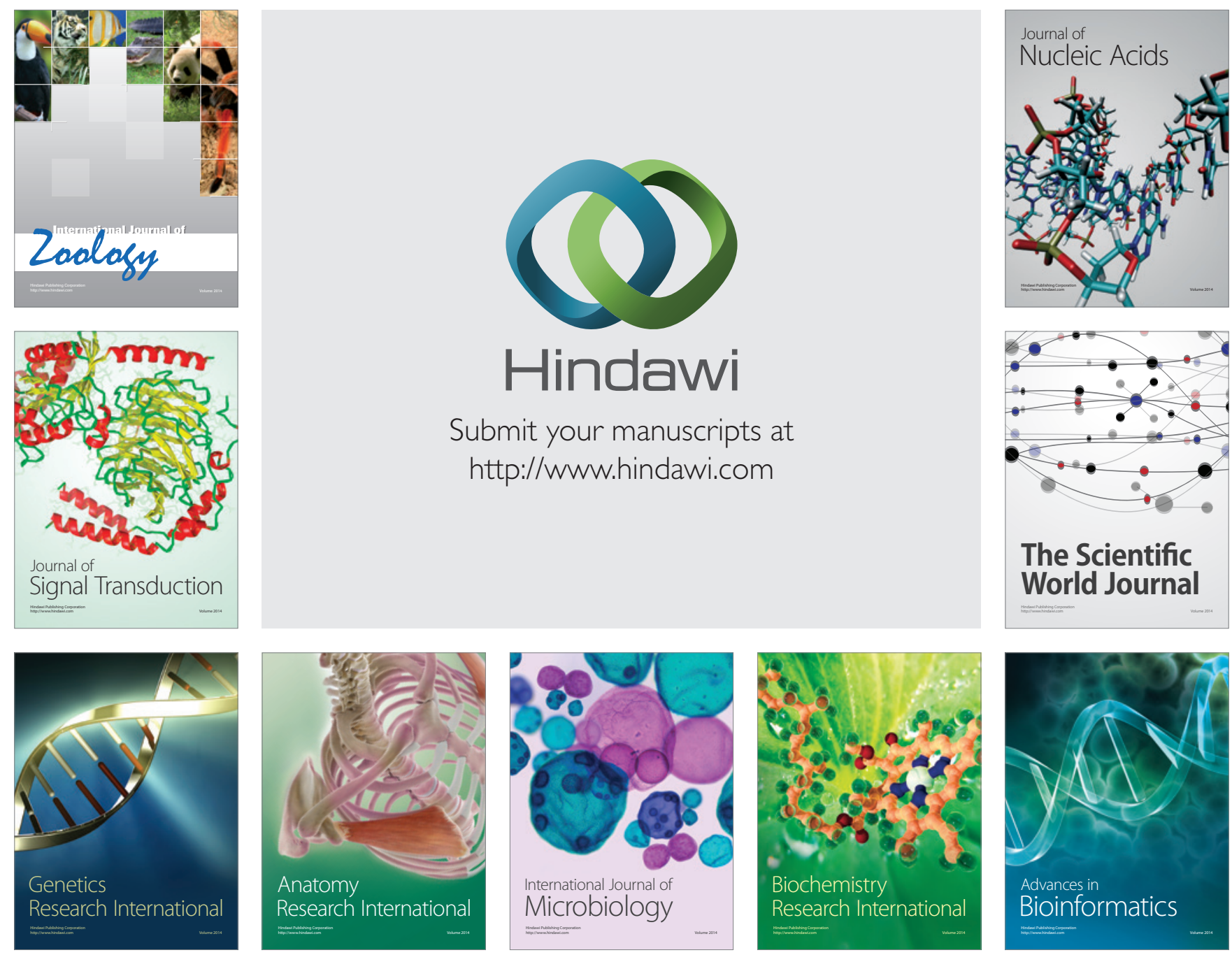

The Scientific World Journal
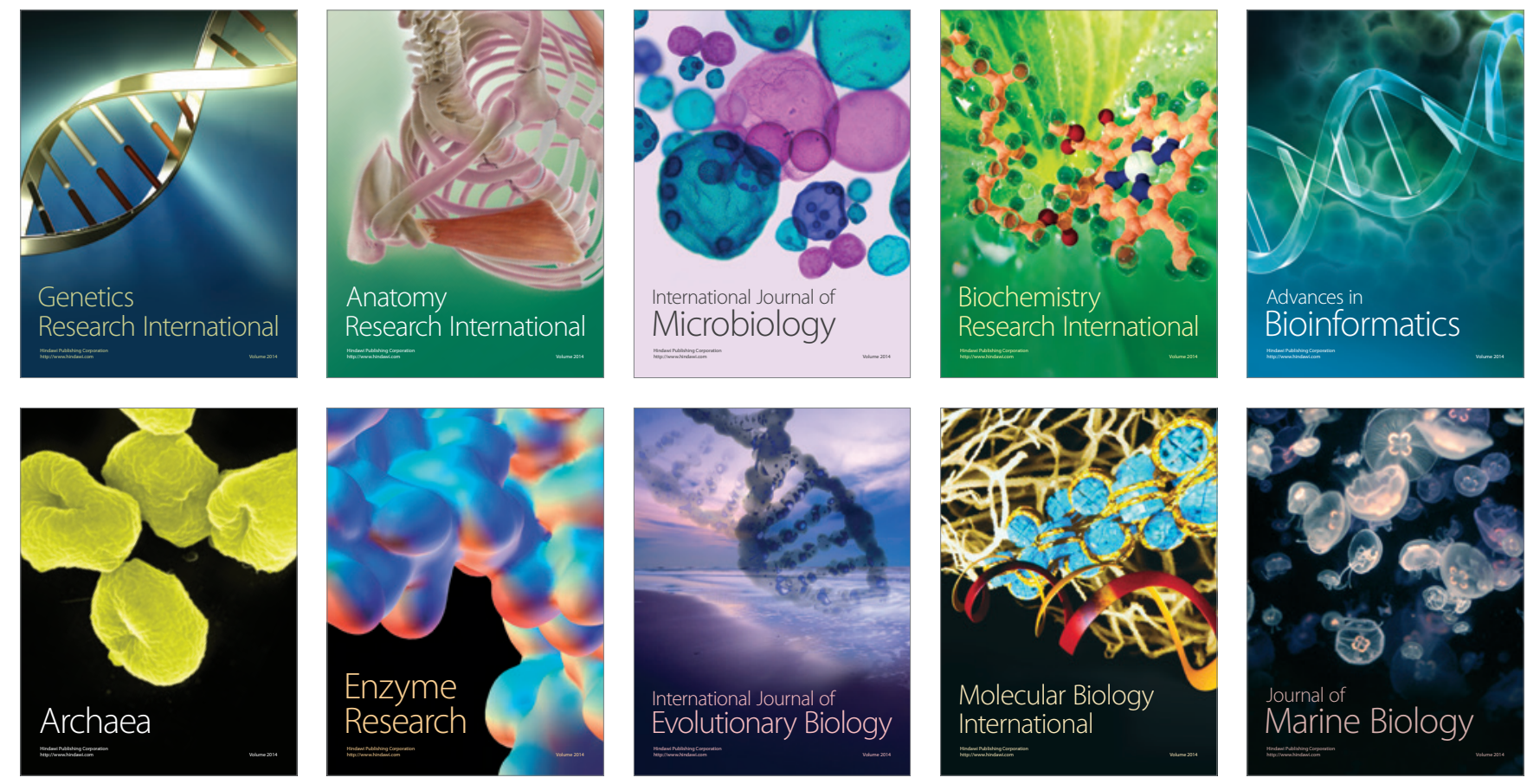